\title{
Charte qualité: transparence, responsabilité et durabilité
}

\section{Christoph Bosshard}

Dr méd., vice-président de la FMH, responsable du département Données, démographie et qualité

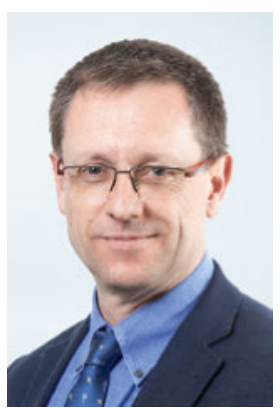

L'activité médicale est basée sur la responsabilité du médecin face à ses patients, et la qualité de sa prestation fait naturellement partie de son travail. Souhaitant regrouper les activités des médecins en faveur de la qualité et les rendre plus visibles, la FMH a fondé en novembre 2012 l'Académie suisse pour la qualité en médecine (ASQM). Les évolutions politiques et sociales actuelles en matière de santé exigent quant à elles de plus en plus fréquemment que l'évaluation des prestations médicales repose sur des critères axés sur la qualité. Dans le domaine de l'admission des médecins, la FMH a également souligné à de nombreuses reprises l'importance de critères de qualité nationaux pour les médecins souhaitant exercer en Suisse: pour elle, des compétences linguistiques obligatoires dans la langue du lieu de travail assorties d'au moins trois ans d'activité dans un établissement de formation postgraduée suisse reconnu dans la discipline visée pour l'admission et d'au moins 5500 heures d'études de médecine sont décisifs pour assurer la sécurité des patients.

\section{Une adhésion claire du corps médical et} des exigences communes envers le monde politique, l'administration et les organisations médicales.

La qualité fait partie intégrante du quotidien des médecins, et c'est pourquoi les sociétés de discipline, les organisations cantonales de médecine et les sociétés faîtières sont appelées à développer et à garantir des stratégies qualité et à élaborer une attestation transparente de la qualité fournie. La charte qualité de l'ASQM leur offre une précieuse vue d'ensemble à cet égard et garantit le transfert de connaissances. Par leur signature, les organisations médicales suisses s'engagent à respecter les principes fondamentaux de la qualité en matière de transparence, d'obligation, de durabilité, de compétences et de ressources, tout en formulant des exigences communes envers le monde politique, l'administration et d'autres organisations médicales.

Comme évoqué plus haut, la qualité des prestations est une dimension incontestée du travail des médecins.
Les exigences croissantes envers le corps médical de documenter et d'attester séparément cette qualité requièrent toutefois clairement des ressources supplémentaires. Nous ne pouvons pas nous permettre de consacrer encore davantage de temps à des tâches administratives au détriment du temps - déjà rare-passé avec nos patients. Il s'agit donc de trouver les moyens pour soutenir les médecins dans cette tâche avec l'appui financier des donneurs de mandat de l'administration et du monde politique.

Pendant deux ans, les délégués du Forum Qualité de l'ASQM ont élaboré une charte qualité qui a ensuite été

\section{Le caractère facultatif ouvre la voie à une} culture de la confiance qui place la motivation et la conviction avant l'obligation et le contrôle.

mise en consultation auprès de toutes organisations représentées à la Chambre médicale; plus de la moitié a répondu à cette invitation avec un écho majoritairement positif. En juin 2016, le Forum Qualité a approuvé la version finalisée de la charte. Après l'aval du Comité central de la FMH et la présentation de la charte à l'Assemblée des délégués, toutes les organisations représentées à la Chambre médicale ont été invitées à la signer.

La première signature symbolique a eu lieu le 27 octobre 2016 lors de la Chambre médicale. La signature de la charte qualité reste facultative et il est possible de la signer à tout moment. C'est précisément ce caractère facultatif qui constitue la base d'une culture de la confiance empreinte d'ouverture et de loyauté. Cette culture place la motivation et la conviction avant l'obligation et le contrôle. Elle représente par ailleurs la condition sine qua non de la réussite d'un système quel qu'il soit, à l'instar du Critical Incident Reporting System.

J'encourage toutes les personnes impliquées à faire preuve de toute la diligence nécessaire dans ce domaine pour que nous puissions continuer de développer notre engagement en faveur de la charte qualité de l'ASQM. 